LWSA

PAPER - OPEN ACCESS

\title{
Peranan Keadilan Organisasi Terhadap Employee Engagement di Masa Perubahan Organisasi
}

\author{
Author : Sherry Hadiyani \\ DOI $\quad: 10.32734 /$ lwsa.v1i2.208 \\ Electronic ISSN : :2654-7066 \\ Print ISSN :2654-7058
}

Volume 1 Issue 2 - 2018 TALENTA Conference Series: Local Wisdom, Social and Arts

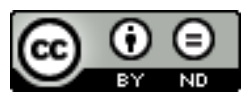

This work is licensed under a Creative Commons Attribution-NoDerivatives 4.0 International License.

Published under licence by TALENTA Publisher, Universitas Sumatera Utara
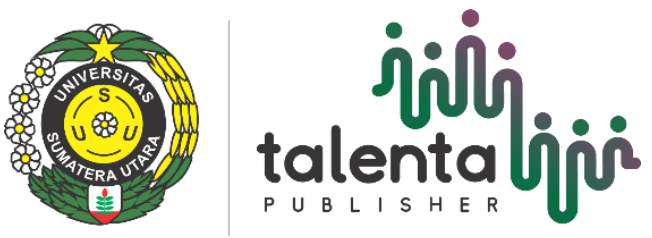


\title{
inji talenta ijọ TALENTA Conference Series \\ Available online at https://talentaconfseries.usu.ac.id
}

\section{Peranan Keadilan Organisasi Terhadap Employee Engagement di}

\section{Masa Perubahan Organisasi}

\author{
Sherry Hadiyani ${ }^{a}$, Siti Zahreni ${ }^{a}$, Fahmi Ananda ${ }^{a}$ \\ ${ }^{a}$ Fakultas Psikologi, Universitas Sumatera Utara, Medan, Indonesia, 20155 \\ sherryhadiyani@gmail.com
}

\begin{abstract}
Abstrak
Perubahan telah menjadi kebutuhan primer bagi kehidupan organisasi. Ketika organisasi melakukan perubahan, employee engagement menjadi elemen penting dalam proses perubahan (Saks, 2006). Karyawan yang mempunyai engagement terhadap perusahaan akan mampu berkontribusi terhadap kesuksesan organisasi dalam menghadapi persaingan maupun tantangan pada serta era globalisasi, menghasilkan pekerjaan yang lebih produktif dan kecenderungan turnover yang rendah. Menurut Saks (2006), faktor yang mempengaruhi employee engagement adalah keadilan organisasi, terutama keadilan distributifdan keadilan prosedural. Individu menginginkan adanya keadilan yang diberikan dari organisasi kepada mereka. Individu juga membandingkan apa yang sudah ia berikan kepada organisasi dengan apa yang sudah ia terima. Kondisi yang seimbang antara apa yang telah diberikan dengan apa yang telah diperoleh akan menimbulkan persepsi yang sama mengenai keadilan dalam organisasi dari sisi karyawan dan organisasi (Aryee, Budhwar\& Chen, 2002). Oleh karena itu, penelitian ini bertujuan untuk mengetahui peranan keadilan organisasi terhadap employee engagement karyawan di masa perubahan organisasi. Subjek penelitian ini adalah karyawan PT. perkebunan X sejumlah 150 orang. Alat ukur yang digunakan adalah skala EmployeeEngagement yang merupakan pengembangan skala Utrecht Work Engagement Scale (UWES) berdasarkan teori Schaufeli \& Bakker (2003) dan skala keadilan organisasi yang dikembangkan berdasarkan skala yang disusun oleh Colquitt (2001). Analisis data menggunakan regresi linier berganda.Hasil penelitian ini menunjukkan bahwa keadilan organisasi memiliki pengaruh positif yang signifikan terhadap employee engagement.Jika dilihat per dimensi, hanya dimensi keadilan procedural yang memiliki pengaruh signifikan terhadap employee engagement.
\end{abstract}

Kata Kunci: Keadilan organisasi; employee engagement

\section{Pendahuluan}

Sektor perkebunan dianggap sebagai salah satu pilar kekuatan ekonomi nasional.BUMN Perkebunan memiliki potensi pertumbuhan yang sangat besar mengingat total lahan yang dikelola sangat luas dengan lokasi dan kualitas lahan yang relative cocok untuk berbagai komoditas perkebunan, memiliki sumber daya yang cukup baik, berpotensi untuk melakukan pengembangan usaha serta didukung oleh pasar baik domestik maupun luar negeri yang relative 
terus berkembang (Muluk, Diponegoro, Lubis, 2007). Dalam menghadapi perkembangan ini tentunya perusahaan perlu melakukan serangkaian perubahan terkait strategi maupun cara pengelolaan sumber daya di dalam perusahaan karena organisasi yang tidak beradaptasi dengan perubahan akan dikalahkan oleh kompetitor yang akhirnya tidak akan mampu mempertahankan eksistensinya (Hussey, 2007).

Ketika organisasi melakukan perubahan, employee engagement menjadi elemen penting dalam proses perubahan tersebut. Schaaufeli, Salanova \& Bakker (2001) menjelaskan engagement sebagai keadaan pikiran yang positif, terpuaskan, berhubungan dengan pekerjaan yang dikarakteristikkan dengan vigor, dedication dan absorption.Karyawan yang mempunyai engagement terhadap perusahaan akan mampu berkontribusi terhadap kesuksesan organisasi dalam menghadapi persaingan maupun tantangan pada era globalisasi dan menghasilkan pekerjaan yang lebih produktif, serta memiliki kecenderungan turnover yang rendah (Saks, 2006), karena salah satu faktor yang mempengaruhi kesiapan karyawan untuk berubah adalah employee engagement (Zulkarnain \& Hadiyani, 2014). Meski demikian beberapa survei menunjukkan bahwa tingkat engagement pada karyawan masih tergolong rendah. Seperti hasil survei yang dilakukan oleh Kenexa Institute pada tahun 2012 menunjukkan bahwa Indonesia memiliki skor sebesar 49\% dari dua puluh delapan negara. Data tersebut menunjukkan Indonesia termasuk dalam kategori yang rendah, sementara skor engagement tertinggi berasal dari negara India sebesar $77 \%$. Hal serupa juga didapatkan melalui survei Global Workforce Studytahun 2012 yang mengikutkan 29 negara termasuk Indonesia dengan total responden 32.000 karyawan. Hasilnya menunjukkan bahwa dua pertiga karyawan di Indonesia tidak memiliki engagement yang tinggi terhadap organisasinya.Dengan demikian, hasil dari kedua survei tersebut menunjukkan karyawan di Indonesia saat ini tergolong karyawan yang disengaged terhadap perusahaan.

Saks (2006) menyatakan bahwa faktor yang mempengaruhi employee engagement dalam diri karyawan adalah keadilan organisasi, terutama keadilan distributifdan keadilan prosedural.Individu menginginkan adanya keadilan yang diberikan dari organisasi kepada mereka. Individu juga membandingkan apa yang sudah ia berikan kepada organisasi dengan apa yang sudah ia terima. Kondisi yang seimbang antara apa yang telah diberikan dengan apa yang telah diperoleh akan menimbulkan persepsi yang sama mengenai keadilan dalam organisasi dari sisi karyawan dan organisasi (Aryee, Budhwar\& Chen, 2002). Keadilan organisasi memiliki empat dimensi utama yaitu keadilan distributif (perbandingan antara hasil yang diperoleh seseorang dengan hasil yang diperoleh karyawan lain), keadilan prosedural (keadilan dari proses bagaimana keputusan organisasi ditentukan), keadilan interpersonal (keadilan yang didapatkan melalui interaksi interpersonal saat menegakkan prosedur), dan keadilan informasional (melalui memberikan informasi tentang proses dan prosedur dalam mengambil keputusan) (Colquitt, 2001).Berkurangnya keadilan yang dianggap oleh karyawan dapat memperburuk burnout, sementara persepsi keadilan organisasi yang dinilai positif oleh karyawan dapat meningkatkan komitmen, kepuasan, produktivitas, dan meminimalisir tingkat absensi pekerja serta dapat memperbaki penurunan tingkat employee engagement (Maslach et al., 2001).

Oleh karena itu, penelitian ini bertujuan untuk mengetahui berapa besar peranan keadilan organisasi dalam membentukengagement karyawan perkebunan pada masa perubahan organisasi.

\section{Bahan dan Metode}

\subsection{Lokasi Penelitian}

Penelitian dilakukan di PT. perkebunan X Rambong Sialang Estate yaitu Divisi 01 (Egaharap), Divisi 02 (Pondok Uling), Divisi 03 (Panglong), Divisi 04 (Firdaus), Divisi 07 (Transport).

\subsection{Metode}

Penelitian dilakukan pada tanggal 31 Agustus 2017 dengan menyebarkan dua buah skala yaitu skala keadilan organisasi dan skala employee engagement kepada 150 orang karyawan PT. perkebunan X. Skala employeeengagement merupakan pengembangan skala Utrecht Work Engagement Scale (UWES) berdasarkan teori Schaufeli \& Bakker (2003). Aitem-aitem dalam skala employee engagement merupakan pernyataan yang terdiri aitem-aitem favorable dan unfavorable dengan enam pilihan jawaban, yaitu Tidak Pernah (TP), Jarang (J), Kadangkadang (K), Sering (S), Sangat Sering (SS), dan Selalu (SL). Skala ini terdiri dari 12 aitem setelah uji coba dengan 
koefisien Alpha sebesar 0.766.Skala keadilan organisasi dikembangkan berdasarkan skala yang disusun oleh Colquitt (2001). Aitem-aitem dalam skala keadilan organisasi merupakan pernyataan yang terdiri dari aitem-aitem favorable dan unfavorable dengan lima pilihan jawaban, yaitu Sangat Sesuai (SS), Sesuai (S), Netral (N), Tidak Sesuai (TS), dan Sangat Tidak Sesuai (STS). Skala ini terdiri dari 33 aitem setelah uji coba dengan koefisien Alpha sebesar 0.902. Metode analisis data yang digunakan dalam penelitian ini adalah analisis regresi linier berganda.

\section{Hasil}

Hasil yang diperoleh dari penelitian ini dapat dilihat pada tabel-tabel berikut :

Tabel 1. Ringkasan Korelasi Pearson

\begin{tabular}{ll}
\hline Variabel Bebas & Employee Engagement \\
\hline Keadilan organisasi & $.425^{* *}$ \\
Keadilan distributive & $.335^{* *}$ \\
Keadilan procedural & $.409^{* *}$ \\
Keadilan interpersonal & $.330^{* *}$ \\
Keadilan informasional & $.379^{* *}$ \\
$* * \mathrm{p}<0,05$ &
\end{tabular}

Berdasarkan table 1, dapat dilihat bahwa keadilan organisasi berkorelasi positif dan signifikan dengan employee engagement. Dimensi-dimensi keadilan organisasi juga berkorelasi positif dan signifikan dengan employee engagement.Selanjutnya dilakukan analisis regresi untuk menentukan kontribusi variable keadilan organisasi terhadap employee engagement.

Tabel 2. Anova

\begin{tabular}{ll}
\hline Variabel Bebas & Employee Engagement \\
\hline Keadilan organisasi & $.425^{* *}$ \\
Keadilan distributive & $.335^{* *}$ \\
Keadilan procedural & $.409^{* *}$ \\
Keadilan interpersonal & $.330^{* *}$ \\
Keadilan informasional & $.379^{* *}$ \\
\hline
\end{tabular}

a. Predictors: (Constant), keadilan informasional, keadilan distributif, keadilan prosedural, keadilan interpersonal

b. Dependent Variable: employee engagement

Dari tabel 2, diperoleh nilai $\mathrm{F}=8,663$ dan $\mathrm{p}=0,00(<0,05)$, maka dapat disimpulkan bahwa keadilan organisasi memiliki pengaruh signifikan terhadap employee engagement

Tabel 3. Model Summary

\begin{tabular}{|c|c|c|c|c|c|c|c|c|c|}
\hline \multirow[b]{2}{*}{ Model } & \multirow[b]{2}{*}{$\mathrm{R}$} & \multirow[b]{2}{*}{ R Square } & \multirow{2}{*}{$\begin{array}{l}\text { Adjusted R } \\
\text { Square }\end{array}$} & \multirow{2}{*}{$\begin{array}{l}\text { Std. Error of } \\
\text { the Estimate }\end{array}$} & \multicolumn{5}{|c|}{ Change Statistics } \\
\hline & & & & & $\begin{array}{l}\text { R Square } \\
\text { Change }\end{array}$ & F Change & df1 & df 2 & $\begin{array}{l}\text { Sig. F } \\
\text { Change }\end{array}$ \\
\hline 1 & $.439^{\mathrm{a}}$ & .193 & .171 & 7.52023 & .193 & 8.663 & 4 & 145 & .000 \\
\hline
\end{tabular}

a. Predictors: (Constant), keadilan informasional, keadilan distributif, keadilan prosedural, keadilan interpersonal 
Koefisien determinan ( $\mathrm{R}$ square) yang diperoleh dari analisis pengaruh keadilan organisasi terhadap employee engagement adalah 0,193. Artinya, pengaruh keadilan organisasi terhadap employee engagementadalah sebesar 19,3\%. Artinya keadilan organisasi memberikan sumbangan efektif sebesar 19,3\% dalam memunculkan employee engagement sedangkan sisanya dipengaruhi oleh faktor-faktor lain yang tidak diteliti dalam penelitian ini.

Tabel 4. Koefisien Regresi

\begin{tabular}{|c|c|c|c|c|c|c|}
\hline \multirow[t]{2}{*}{ Model } & & \multicolumn{2}{|c|}{ Unstandardized Coefficients } & \multirow{2}{*}{$\begin{array}{l}\text { Standardized } \\
\text { Coefficients } \\
\text { Beta }\end{array}$} & \multirow[t]{2}{*}{$\mathrm{t}$} & \multirow[t]{2}{*}{ Sig. } \\
\hline & & B & Std. Error & & & \\
\hline \multirow[t]{5}{*}{1} & (Constant) & 29.955 & 4.968 & & 6.029 & .000 \\
\hline & Keadilan distributive & .222 & .252 & .090 & .882 & .379 \\
\hline & Keadilan procedural & .384 & .186 & .244 & 2.069 & .040 \\
\hline & Keadilan interpersonal & -.035 & .179 & -.023 & -.197 & .844 \\
\hline & Keadilan informasional & .322 & .194 & .186 & 1.663 & .098 \\
\hline
\end{tabular}

Tabel 4 menunjukkan bahwa jika variable keadilan organisasi ditinjau per dimensi, hanya dimensi keadilan procedural yang berpengaruh signifikan terhadap employee engagement $(0,40 ; p<0,05)$ sedangkan dimensi keadilan distributive $(0,379 ; \mathrm{p}>0,05)$, dimensi keadilan interpersonal $(0,844 ;$ dist $>0,05)$, dimensi keadilan informasional $(0,098 ; p<0,05)$ tidak berpengaruh signifikan terhadap employee engagement. Dengan demikian persamaan garis regresinya adalah sebagai berikut $: \mathrm{Y}=29.955+0.222 \mathrm{X} 1+0.384 \mathrm{X} 2-0.035 \mathrm{X} 3+0.322 \mathrm{X} 4$

\section{Pembahasan}

Penelitian ini bertujuan untuk melihat peranan keadilan organisasi terhadap employee engagement karyawan PT. perkebunan X. Hasil analisis data menunjukkan bahwa bahwa keadilan organisasi memiliki pengaruh positif yang sifnifikan terhadap employee engagementkaryawan PT. perkebunan X. Artinya semakin tinggi keadilan yang dirasakan karyawan di dalam organisasi maka semakin meningkat pula engagement karyawan. Hasil analisis penelitian juga menemukan besaran pengaruh keadilan organisasi terhadap employee engagement. Keadilan organisasi mempengaruhi employee engagement sebesar 19,3\% sedangkan sisanya (80,7\%) dipengaruhi oleh factorfaktor lain yang tidak diteliti dalam penelitian ini.

Hasil penelitian ini sejalan dengan penelitian yang dilakukan Saks (2006) tentang anteseden dan konsekuensi dari engagement, yang menunjukkan salah satu prediktor yang signifikan terhadap munculnya engagement pada karyawan dengan pekerjaannya adalah keadilan organisasi. Hal ini juga sesuai dengan yang dikemukakan Barling \& Phillips (1993) bahwa ketika karyawan merasa diperlakukan adil, mereka akan cenderung melakukan perilaku prososial terhadap organisasi seperti engagement. Sejalan dengan itu, Cropanzano \& Mitchell (2005) juga menyatakan bahwa ketika karyawan merasakan adanya keadilan yang tinggi di dalam organisasinya, maka mereka juga akan memiliki perasaan yang berkewajiban untuk menjadi adil dengan meningkatkan perilaku engagement.

Disamping ingin melihat pengaruh keadilan organisasi secara keseluruhan, penelitian ini juga ingin melihat pengaruh masing-masing dimensi keadilan organisasi terhadap employee engagement. Hasilnya menunjukkan bahwa hanya dimensi keadilan procedural yang berpengaruh signifikan terhadap employee engagement sedangkan dimensi keadilan distributive, dimensi keadilan interpersonal dan dimensi keadilan informasional tidak berpengaruh signifikan terhadap employee engagement.Hal ini tidak sejalan dengan penelitian Ghosh \& Rai (2014) yang menunjukkan bahwa dimensi keadilan distributive dan keadilan interaksional bisa dilihat sebagai alat untuk meningkatkan employee engagement karena peran fungsionalnya dalam mencapai tujuan. 


\section{Kesimpulan dan Saran}

Berdasarkan hasil penelitian yang diperoleh, maka dapat disimpulkan bahwa :

1. Keadilan organisasi memiliki pengaruh positif yang signifikan terhadap employee engagement pada karyawan PT. perkebunan X. Artinya keadilan organisasi berperan terhadap employee engagement. Semakin tinggi tingkat keadilan organisasi maka akan semakin tinggi tingkat engagement karyawan.

2. Pengaruh keadilan organisasi terhadap employee engagement pada karyawan PT. perkebunan X adalah sebesar 19,3\%. Artinya keadilan organisasi memberikan sumbangan efektif sebesar 19,3\% dalam memunculkan employee engagement sedangkan sisanya dipengaruhi oleh faktor-faktor lain yang tidak diteliti dalam penelitian ini.

3. Jika variable keadilan organisasi dianalisis per dimensi, hanya dimensi keadilan prosedural yang berpengaruh signifikan terhadap employee engagement.

Berdasarkan penelitian yang telah dilakukan dan hasil yang telah dipaparkan, saran yang dapat disampaikan adalah peneliti selanjutnya hendaknya menggunakan jumlah sampel yang lebih besar agar hasil penelitian yang diperoleh lebih valid dan reliable.

\subsection{Ucapan Terima Kasih}

Penelitian ini merupakan Penelitian Keunggulan Akademik (TALENTA) USU T.A USU Tahun Anggaran 2017 skim Dosen Muda. Oleh karenanya, pada kesempatan ini penulis hendak menyampaikan terima kasih kepada semua pihak yang telah memberikan dukungan moril maupun materiil sehingga penelitian ini dapat selesai. Ucapan terima kasih ini penulis tujukan kepada :

1. Bapak Prof. Dr. Runtung, S.H., M.Hum, selaku Rektor Universitas Sumatera Utara

2. Bapak Prof. Dr. Emran Munir, M.Sc., selaku Ketua Lembaga Penelitian Universitas Sumatera Utara selaku Dekan Fakultas Psikologi

3. Bapak Zulkarnain, Ph.D, Psikolog selaku Dekan Fakultas Psikologi Universitas Sumatera Utara.

4. Segenap pimpinan serta karyawan PT. perkebunan X.

\section{References}

[1] Saks, A. M. (2006). Antecedents and Consequences of Employee Engagement.Journal of Managerial Psychology, 21(7), 600-619. https://doi.org/10.1108/02683940610690169.

[2] Aryee, S., Budhwar, P. S., \&Chen, Z. X. (2002). Trust as mediator of the relationship between organizational justice and work outcomes; Test of a social exchange model. Journal of Organizational Behavior, 23(May), 267-285. https://doi.org/10.1002/job.138.

[3] Schaufeli, W. B., Bakker, A. B. (2003). UWES-Utrecht Work Engagagement Scale Preliminary Manual.Occupational Health Psychology Unit Utrecht University.

[4] Colquitt, J. A. (2001). On the dimensionality of organizational justice: a construct validation of a measure. Journal of applied psychology, 86(3), 386.

[5] Muluk, C., Diponegoro, A. \& Lubis, I. F. (2007). Restrukturisasi BUMN perkebunan melalui holding company.Jurnal Transformasi Bisnis, 2(5), 10-18.

[6] Hussey, D. E. (2000), How to manage organization change.London : Kagan page.

[7] Schaufeli, W. B., Salanova, M., Gon Alezro, V. A., \& Bakker, A. B. (2001). The Measurement of Engagement and Burnout; a Two Sample Confirmatory Factor Analytuc Approach. Journal of Happiness Studies, 3, 71-92. https://doi.org/10.1023/A:1015630930326.

[8] Zulkarnain \& Hadiyani (2014). Peranan komitmen organisasi dan employee engagement terhadap kesiapan berubah karyawan.Tesis. Fakultas Psikologi. Universitas Sumatera Utara.

[9] Maslach, C., Schaufeli, W. B., \& Leiter, M. P. (2001). Burnout.Control, 397-422. https://doi.org/10.1146/annurev.psyvh.52.1.397.

[10] Cronpanzano, R., \& Mitchell, M. S. (2005). Social Exchange Theory;An Interdisciplinary Review. Journal of Management, 31(6), 874-900. http://doi.org/10.1177/0149206305279602.

[11] Ghosh, P., Rai, A. (2014). Organizational justice and employee engagement; Exploring the linkage in public sector banks in India. Personal Review, 43(4), 628-652 